\title{
Informed consent: ideal or reality?
}

Priscilla Alderson

Journal of Health Services Research and Policy, 3, 2: 124-6

\begin{abstract}
This paper reviews standards of informed consent set by ethicists and lawyers, and research about consent by social scientists. Consent to medical and social health services research, with the added complications of consent to interventions on children, are discussed. Paradoxical meanings are considered, of consent as an informed correct choice or a courageous best guess, and of autonomy as isolated, uncompromised freedom or reasonably uncoerced self-realisation. Beyond being informed, consent involves evaluating, making and signifying a decision; it is better understood as a process than an event, in which reasoned understandings can be complemented by emotional insights. Ethical and legal standards of voluntary consent, though partly an unrealistic ideal, provide important guidelines for people who request and give consent to research.
\end{abstract}

\section{Introduction}

Is it ever possible to give informed consent to health treatment or research? Are the standards of consent set by ethicists and lawyers too high for ordinary people to reach? Should these standards be abandoned or modified? These questions are discussed in this paper mainly in relation to the extensive literature on consent in medicine, with examples about consent to children's treatment and research which raise extra dilemmas.

\section{Ethicists and consent}

Locke (1) and Kant (2) advocated freely given consent on grounds of property-owning man's pure rationality and independent autonomy. No one else has the right to make personal decisions for him, for that would violate his physical and mental integrity. They excluded women, children and servants as too irrational and dependent to be able to make sensible or voluntary decisions.(3) The three elements of consent are being informed, making and signifying a rational decision, and being free from constraint and coercion. Rationality and freedom are especially associated with adulthood. Childhood is defined by its relatively powerless dependence and supposed immaturity. Childhood is a social rather than a biological state,(4) since many children exceed many adults in size and strength and, traditionally, childhood ends with the "age of consent". The varying ages of consent fixed by different societies illustrate the socially constructed nature of childhood. Although children and many adults may not seem to exercise pure Kantian rationality, their share in the consent stakes might expand when "strong" Kantian autonomy is modified by $\mathbf{J}$ S Mill's "weak" autonomy. Mill argued that liberty is so precious that the personal decisions of all adults should be respected, whether these appear to others as wise or foolish.(5) However, Mill excluded children saying they should be protected from freedom to make risky even selfdestructive decisions until they reach adult autonomy.

Modern notions of consent combine strong and weak autonomy in a paradox: the Kantian ideal of wisdom to make the correct decision, and the Millean ideal of courage to stand by a best guess with the risk of mistakes and bitter regret. Ethicists further complicate their analyses of consent by combining idealism with positivism: the ideal of completely independent, lonely autonomy isolated from all pressures, with positivist acceptance of such terms as "medical information". Dichotomies such as doctor/patient, informed/ignorant, rational/emotional, risk/benefit are accepted as unproblematic, $(6,7)$ rather than as contested and socially constructed concepts. These 
Enlightenment dichotomies delete the uncertain middle ground on which many people negotiate consent. Ethicists clarify concepts which help in the understanding and practice of consent, but this very clarity can also be unrealistic and unhelpful.

\section{Lawyers and consent}

Respect for autonomy can be traced through Anglo-American case law, "Every human being of adult years and sound mind has the right to determine what shall be done with his own body, (8)and also through international legal guidance on medical research: " 1 . The voluntary consent of the human subject is absolutely essential...free power of choice without the intervention of any element of force, fraud, deceit, duress, overreaching, or ulterior form of constraint or coercion; [the person] should have sufficient knowledge and comprehension of the elements of the subject matter involved as to enable him to make an understanding and enlightened decision". (9) Nuremberg lawyers assumed that average adults can make an enlightened decision provided they are adequately informed; they vetoed research on minors.

The more ambiguous Declaration of Helsinki (10) emphasises lay people's difficulty in understanding complex research which is vital to aid "suffering humanity", and stresses researchers' discretion rather than research subjects' consent. Research on children is permitted provided the benefits exceed the risks. In English law, the "reasonable doctor" decides how much information is needed for consent to be informed (11) whereas in some North American states the "prudent patient" decides.(12) Some English lawyers consider that doctors should be more informative.(13) In the UK, minors can give valid consent to treatment when they have "sufficient understanding and intelligence to understand fully what is proposed" and "sufficient discretion to .. make a wise choice in [their] own interests",(14) although this ruling has been qualified and complicated by later Court of Appeal cases.(15). The treating doctor decides whether the minor is competent (16) and in practice some parents and health professionals treat experienced young children as competent to make complex major decisions.(17) Research is regulated by guidance, in the absence of legislation, and some lawyers advise that, for research with minors, parents' consent must always be requested (18) but the guidance is contradictory.(19) Health researchers do not have to have research ethics committee (REC) approval, though the absence of such approval would be an aggravating factor in any criminal prosecution for assault or civil action for battery or negligence arising from harm to research subjects. Guidance is confused by the term "therapeutic research". As an investigation, research cannot be therapy; it can only examine therapy. The term is loosely applied to groups who do not benefit because they are in placebo arms or have treatments which turn out to be useless or harmful. The law unfortunately concentrates on preventing bad practice, and sets low minimum standards of consent, whereas professional bodies could promote higher standards through Codes of Practice which have quasi-legal status.(20)

\section{Social science research on consent}

Psychologists have conducted many surveys of patients' consent.(21) They tend to reduce consent to patients' ability to recount medical information, and ignore the stages when people actively evaluate and decide. They also tend to examine what patients remember but not what they were told, and attribute ignorance to patents' difficulties in understanding and not also to doctors' difficulties in explaining. Refusal is often seen as an ignorant mistake, but broader social science studies of "non-compliance" in taking prescribed drugs (22) and of medical research without consent (23) strengthen the case for respecting patients' independent consent or refusal. Empirical studies which take account of the social context bridge the ethicists' dichotomies by 
showing how medical information is evaluated through personal experience and moral feelings.(24) "Non-compliant" adolescents, who become more lax about controlling conditions such as diabetes, can be seen as responsible rather than rebellious in trying to balance their health and social interests as adults do.(25)

Theoretical work on consent shows how political movements and mass media misinformation "manufacture" consent, shaping people's values against their better judgement.(26) Ineffective treatments for disabilities (27) and new screening programmes (28) are criticised for creating uninformed demands for and consent to harmful services, and for illustrating how consent can be a means of masking professional power. In effect, the signed consent form transfers power to the practitioner or researcher, and responsibility for any subsequent problems to the patient or subject.

\section{Consent to health services research}

Medical research guidelines, and innovations such as RECs, tend to follow scandals: Helsinki in 1964, and the Thalidomide publicity in 1963, for example. Social science researchers appear to be far less concerned about consent than medical researchers are, perhaps because they assume their work cannot be harmful and certainly not lethal. Yet social research about health can be intrusive and distressing, and can have enormous impact on people's health; research over the past decade about how many beds and hospitals London needs is simply one instance. However, the psychologists' guidelines speak of "participants" but permit covert research,(29) and the extremely brief BSA guidance does not even mention children.(30) Compared with copious medical research guidelines, social research guidance looks casual and urgently needs improving. A particular area of concern is research with children, who are among the hardest groups for researchers to contact, via their parents, practitioners and authorities, increasingly, clearance through police records of child abusers is necessary. Parents' refusal can silence and exclude children who would like to consent and whose views should be heard.

There are several ways in which social researchers might pay more attention to informed consent, and benefit their own work in doing so. Here are some suggestions for discussion taken from more detailed reports. $(20,31)$

* Working groups of the BSA and BPS, liaising with the health professionals' associations, royal colleges and RECs, could prepare guidelines for consultation on setting and assessing standards of consent to various types of social research and by various groups, such as children or confused older people.

* Researchers could be more accountable to their subjects, individually and through self help organisations, working with them at every stage of research from design to implementation of the findings, to promote research in which health service users will more willingly take part.

* It is usual to inform potential subjects about the purpose and nature of the research, and how they will be personally affected and their confidentiality be respected. Yet, to give informed consent, they need to know how the findings might be used, through what kinds of publicity and policy channels, whose interests will be served, and what the impact might be, not only on them but on the whole group they belong to. With teenage mothers or people with HIV, for example, will researchers report them as victims or villains, or as a very mixed group with their own complex understandings? How can health researchers balance impartial research with respect for their subjects' worth and dignity? The process of informed consent can help researchers to resolve this tension, and to work with their subjects on rasing standards in the conduct and findings of health services research.

A pessimistic view of informed consent would see it as an impossible and unhelpful ideal. Few 
patients exhibit the emotionless rationality and intellectual prowess ethicists expect. Indeed, if they are not distressed when facing a risky major intervention, they have probably not understood its severity. Few patients feel able freely to negotiate the legal-contract concept of consent, because it assumes equal bargainers, and ignores doctors' and researchers' greater power and knowledge. Psychologists show that many people fail their information tests. Crucial aspects of research are doubt and ignorance; if all the answers were known the research would be unnecessary and unethical, but uncertainty is one of the hardest parts of the research to explain to potential subjects, though young children can understnad risk and porbability.(17) Social scientists show that the social values and pressures, from which Kantians assume we must escape if we are to be autonomous, are inescapably part of our identity. Without these values and preferences we would have no concept of choice, consent or refusal.

\section{Combining ideal and reality}

Despite the many ambiguities and problems in the theory and practice of consent, the ideal is too important to lose. People can be very disturbed if they find they have been involved in research without their consent.(32) Even if researchers do not respect consent from concern for principles of justice, autonomy and avoiding harm, they would do so from self-interest. Care taken to ensure that research subjects' consent is as informed and freely given as possible is a means of preventing abuse and scandal, undue risks and litigation. It can also prevent the loss of public support, funding, willing research subjects, and interest in implementing research findings, as well as the rejection of research reports by ethical journal editors. Like its prototypes, the democratic vote and consent to proposal of marriage, consent to health research unites idealistic aspirations with self-interested pragmatism.

\section{References}

1. Locke J. An essay concerning human understanding. Book 2.1690.

2. Kant I. Groundwork of the metaphysics of morals. In Paton H, editor. The moral law. London: Hutchinson; 1948.

3. Grimshaw J. Feminism and philosophy. Brighton: Wheatsheaf; 1986.

1964, the World Medical Association agreed more ambiguous Declaration of Helsinki,

4. James A, Prout A, editors. Constructing and reconstructing childhood. London: Falmer; 1990.

5. Mill JS. On Liberty. Harmondsworth: Penguin; 1859/1952.

6. Beauchamp T, Childress J. A history and theory of informed consent. New York: Oxford University Press; 1986.

7. Gillon R. Philosophical medical ethics. Chichester: John Wiley; 1986.

8. Cardozo In Schloendorff v. Society of New York Hospitals 211 NY 125, 1914.

9. Nuremberg Code. 1947. In Duncan A, Dunstan G, Wellbourn R, editors. Dictionary of Medical Ethics. London: Darton, Longman \& Todd; 1981. P.130-132.

10. Declaration of Helsinki. In: The World Medical Association: Handbook of Declarations. Ferney-Voltaire: WMA; 1983.

11. Bolam v. Friern Hospital Management Committee [1957]WLR 582.

12. Kennedy 1.Treat me right. Oxford: Clarendon; 1988.

13. Scarman LJ. Consent communication and responsibility. Journal of the Royal Society of Medicine 1986; 79:697-700.

14. Gillick v. West Norfolk and Wisbech AHA [1985] 3 All ER 410, 421.

15. Montgomery J. Health care law. Oxford; Oxford University Press; 1997.

16. Age of Legal Capacity (Scotland) Act (1991) 2.4 . 
17. Alderson P. Children's consent to surgery. Buckingham: Open University Press; 1993.

18. Royal College of Physicians. Guidelines on research with patients. London: RCP; 1990.

19. Alderson P. Did children change or the guidelines? Bulletin of Medical Ethics 1992; 80:21-8.

20 Alderson P, Montgomery J. Health care choices: making decisions with children. London: Institute for Public Policy Research.

21. Kauffamn C. Informed consent and patient decisions making: two decades of research. Soc. Sci. \& Med. 1983; 17(21):1657-64.

22. Stimson G. Obeying doctors' orders. Soc. Sci. \& Med. 1974; 8(2):97-104.

23. Faulder C. Whose body is it? London: Virago; 1985.

24. Alderson P. Choosing for children: parents' consent to surgery. Oxford: Oxford University Press; 1990.

25. Williams C. The gendered management of chronic illness. Paper at BSA Medical Sociology AGM, 1997.

26. Herman E, Chomsky N. Manufacturing consent. London: Vintage; 1994.

27. Oliver M. Understanding disability from theory to practice. London: Macmillan; 1996.

28. Cunningham-Burley S, Kerr A, Shakespeare T, Watson N. Informed choice and consent. Paper at BSA Medial Sociology AGM, 1997.

29. British Psychological Society. Revised ethical principles for conducting research with human participants. Leicester: BPS; 1991.

30. British Sociological Association. Guidelines for good professional conduct and statement of ethical practice. Durham: BSA; 1993.

31. Alderson P. Listening to children: ethics and social research. Barkingside: Barnardo's; 1995.

32. Goodare H, editor. Fighting spirit. London: Scarlett Press; 1996.

2460 words 